\title{
Editorial: The Violence and Addiction Equation Revisited
}

\author{
Christine Wekerle
}

Published online: 20 July 2011

(C) Springer Science+Business Media, LLC 2011

In April 2010, Masood Zangeneh, Editor-in-Chief, invited me to act as a Special Projects Editor with this journal. The goal for these special projects initiatives is to highlight unique advances in various countries, to consider a broad spectrum of mental health and substance use issues, to spotlight research on emergent clinical issues, under-studied populations, and to bring together global-minded epidemiology, clinical, basic, and implementation science. There is a commitment to provide more parenting and pediatric research in the mental health and addiction areas. Considering that mental health and substance abuse occur and co-occur in contexts of vulnerabilities and resilience, there is an effort to be intervention-minded (screening, assessment, prevention, treatment), as well as to address for whom (moderators), and why (mediators) positive outcomes are obtained. In short, special projects are one effort to enhance coordination and coherence of the multiple factors and systems involved in the content areas of mental health and addiction problems. Finally, there is an intention to move evidence to usability, and to invigorate evaluation of the maintenance and sustainability factors, particularly in times of shifting priorities and resource scarcity. How efficient can we be with excellence? One example is the World Health Organization's VIP webinars series (violence, injury, prevention; http://www.who.int/violence_injury_prevention/en/) provided freely to global stakeholders.

The intention of IJMHA Special Projects is to be proactive in enhancing evidence usability. Knowledge translation (KT) is the exchange, synthesis and ethically-sound application of knowledge (e.g., Graham et al. 2006). Basic fidelity to both science and ethics principles are foundational to any assessment of quality of evidence, with armslength peer review process assessing the ethics information presentation, the nature of engaged review boards, practice guidelines, referencing state-of-knowledge in systematic and meta-analytic reviews, and specifying the practical implications in a clear and tempered manner. There is a market pull (evidence it wants) and push (evidence it does not want), recognizing that faithful, yet flexible implementation is founded upon a long-term view of partnership, and that the implementation process of evidences is a long-term, multi-stage systematic process (Mildon and Shlonsky in press; Toth and Manly in press). As editor of

C. Wekerle $(\bowtie)$

McMaster University, Hamilton, $\mathrm{OH}$, Canada

e-mail: wekerc@mcmaster.ca 
special projects, I plan to pair key articles and their authors with broad exchange opportunities to provide useable extension learning for stakeholders in addiction, mental health, child welfare, shelter and housing services, and so forth. I look forward to working with the IJMHA interest group to craft creative and accessible modes for scholarly interaction.

\section{And Now for Something Completely Different: A Bit About Me}

My first experience with substance abuse was in church as a child at Easter mass, at a time when Spring finery (and white gloves) were worn. In front of our family was a lone homeless man in a pew, with all the common visual and olfactory signals. There is a kindly tradition of turning to those all around you, shaking hands, and wishing them peace. How appropriate! I very much wanted to shake this person's hand, but I feared the reaction of others-social comparison was absolute, no one was entreating this gentleman. My heart sunk as he looked around, and slowly recognizing no approach, turned and left. How sad! Not to be tempted to see this as isolated, the decades of work of Susan Fiske and colleagues has shown consistency across countries on how homeless are viewed within a quadrant of high versus low warmth, and high versus low competence. Across countries, they are placed in the low warmth and low competence, low within that quadrant with "disgust" the applicable affective categorization. In contrast, individuals with visible disabilities are in the high warmth, low competence quadrant, with "pity" as the operative affective stance (Fiske 2011). This intergroup, social cognition, and social emotions work is important to take into consideration as we look to service development, utilization and satisfaction.

Since life is filled with second chances, I found myself a decade later interested in clinical psychology, a university undergraduate, and engaging with the mentally ill and homeless population as a volunteer. My second entry to substance abuse work was in graduate school, looking for research on substance abuse patterns of maltreating parents, while compiling review articles on maltreatment-related interventions (Wekerle and Wolfe 1993; Wolfe and Wekerle 1993; Wekerle and Wolfe 1999) that led to an edited book during my first faculty position, with my graduate school colleague, Anne-Marie Wall, called "The Violence and Addiction Equation" (Wekerle and Wall 2002). At that time, the substance abuse researchers and clinicians had greater engagement with and intervention readiness for dealing with violence factors, than did the violence researchers and clinicians. Yet, parental substance abuse and mental health issues are prominent in maltreating families.

It is acknowledged that current child welfare cases are complex with indices of risk sharing similar outcomes and characteristics as substantiated maltreatment (Fallon et al. 2011). With complex cases, where the child is the client as with child welfare, parental mental health and substances provide a challenge. Resources are available on the US Department of Health and Human Services, Administration for Children and Families significant resource site, Child Welfare Information Gateway (http://www.childwelfare.gov/), as well as the US Substance Abuse and Mental Health Services Administration (http:// www.samhsa.gov/), and its US National Center on Substance Abuse and Child Welfare (http://www.ncsacw.samhsa.gov/training/default.aspx); these provide toolkits, webinars, training opportunities, population outcome statistics, scientific literature updates, practice guidelines materials, and more at no cost to the subscriber. For example, from SAMHSA's data point features, diagrams illustrate the statistic that adult alcohol dependence is four times as likely to be a co-occurring issue (with mental illness), in contrast to when there is no mental illness (http://oas.samhsa.gov/spotlight/Spotlight027AlcoholDependence.pdf). It is suggested that providers working with individuals with either a substance use or a 
mental health problem may want to consider screening for a co-occurring disorder and providing an integrated treatment program. The Wekerle and Wall (2002) contributors discussed such issues as sequencing of treatment, target of treatment, impact of substance treatment on non-targeted, but impacted, violence outcomes and so forth. Substance abuse, mental health and other caregiver vulnerabilities interact with partner violence to predict caseworker maltreatment substantiation decisions (Wekerle et al. 2009). Thorough assessment and collaboration among systems (substance services, police, shelters, child welfare, child and family mental health services) requires on-going attention to the literature and current practice trends.

\section{Two-Issues on Risk and Resilience: The Impact of Childhood Maltreatment}

The focus in these two issues is on child maltreatment - a robust risk factor for a host of poor outcomes (Wekerle 2011). Child maltreatment is a stressor event and a stressful lifestyle. Physical, sexual, emotional abuse and neglect all involve some level of attack to the child's body and mind. Maltreatment has been shown to cluster with other adverse childhood events and predict onset of DSM-IV disorders (Green et al. 2010), as well as persistence of disorders (substance, mood, anxiety; McLaughlin et al. 2010). These domains of at-risk health conditions appear logically clustered towards the psychological, physical, and interpersonal response to unremitting high, and often unpredictable, daily stress from danger, violence and their threat while growing up. Maltreatment, a preventable adult action towards a child, places the victim in further contexts of vulnerability. For example, compared to matched controls, maltreated children find as adults their peak earnings are about $\$ 5,000$ less/year that, over time, is a sizeable financial impairment (Currie and Widom 2010). Importantly, females bear a greater breadth of burden as compared to maltreated males, showing significant less grade attainment, income, IQ test score (at young adulthood), and ownership (vehicle, home, bank account). In this US substantiated large-scale sample followed through adulthood, maltreatment is especially problematic for women's mental, physical, and financial health.

Within the types of maltreatment, emotional maltreatment tends to be under-attended for its impact on self-functioning, including stable, coherent self-view that supports self-care and counters suicidality (e.g., Cicchetti et al. 2009; Yates and Wekerle 2009). Negative social self-learning has also been identified as a core issue for adult children of alcoholics (e.g., Wall and McKee 2002; Webb et al. 1992). Emotional or psychological maltreatment is a pattern of interacting with children or a child (targeted or scapegoat role), reflecting the lack of emotional nurturance (e.g., never saying "I love you.") and positive discovery opportunities, as well as the presence of emotionally hurtful communications and interactions (e.g., consistently ignoring, denigration, Trickett et al. 2009). Often, condemnations of the child as a person are repeated and persist over time. The World Studies of Abuse in the Family Environment (WorldSAFE study; Sadowski et al. 2004), which utilizes common measures across surveyed countries, indicates that $25 \%$ of parents report that they "pulled the child's hair" in the past 6 months; and $15 \%$ to $44 \%$ of parents reported calling children names. According to the US National Survey of Children's Exposure to Violence (Finkelhor et al. 2010), 22.6\% positively endorsed the single emotional abuse item that included frightened affect (getting scared or feeling really bad) about adult-to-child verbal abuse (called names; mean things said; told you weren't wanted). In terms of reports to child welfare, the US National Incidence Study places psychological abuse at $27 \%$ of the cases, and psychological neglect at $25 \%$ of the cases, 
when using the corollary that demonstrated harm occurred to the child. When risk of harm (endangerment) is considered, a broader incidence is found: $36 \%$ of children are emotionally abused (Report available at: http://www.acf.hhs.gov/programs/opre/abuse_neglect/natlincid/ nis4_report_congress_full_pdf_jan2010.pdf).

The World Report on Violence and Health (WHO; Krug et al. 2002) reports that partner violence and child maltreatment commonly co-occur. Intimate partner violence is abuse that occurs between two people in a close, typically romantic, relationship. The term intimate partner violence (IPV) reflects physical, emotional, and sexual abuse in a close relationship, with current and former spouses and dating partners; (www.cdc.gov/violenceprevention/ pdf/IPV_Strategic_Direction_One-Pager-a.pdf). The Canadian Maternity Experience Survey (2006-2007; http://www.phac-aspc.gc.ca/rhs-ssg/survey-eng.php) found that $40 \%$ of the 15 to 19 year old mothers experienced physical and/or sexual partner abuse in the prior two years, and this group reported the highest pregnancy stress (e.g., moved to a new address, argued with partner more than usual). These younger women reported family, friends and health care providers as nearly equivalent information resources. When either the mother alone is a victim of IPV or when both parents engage in IPV, parental aggression to the child becomes more likely (e.g., Taylor et al. 2010). Substantiation of other forms of maltreatment was found at greater levels when partner violence was present alongside primary caregiver vulnerabilities (e.g., substance abuse; Wekerle et al. 2007). In some areas, exposure to IPV is a form of emotional abuse. From population survey, where $10.3 \%$ of US children were maltreatment victims; among 14 to 17 year old youth, more than one-third had seen their parent(s) assaulted (Finkelhor et al. 2010). According to the 2008 CIS statistics, where IPV exposure is separated out from other forms of emotional abuse, IPV exposure was a leading category of substantiated child maltreatment (34\%); $9 \%$ of cases were substantiated as emotional abuse. The most common co-occurrences being IPV exposure and neglect (Public Health Agency of Canada 2010; Trocmé et al. 2010). According to the emotion regulation hypothesis (e.g., Stewart 1996; Stewart and Israeli 2002) self-harming (Jacobson and Gould 2007; Ross and Heath 2003; Laye-Gindhu and Schonert-Reich 2005) or aggressive behaviours (Gordis et al. 2009) may be an attempt to regulate (i.e., decrease or distract from) the experience of negative emotions (coping motive, Kuntsche et al. 2008; Grant et al. 2009; Cooper et al. 1992), among others. Substance use imparts physiological changes; escalating use patterns provide a psychological context that is perceived as effective, if not efficient, by the user.

However, the role of historical and on-going trauma is substantial in impairment (e.g., Gilbert et al. 2009; Wekerle 2011). When oneself is seen as negative, traumatic stress may heighten the overall negative burden load via: (1) over-experiencing negative selfemotions (i.e., shame, rejection, anxiety etc.: too many types, too frequently, too intensely); (2) over-engagement in self-punishing behaviours (e.g., self-harming acts; self-neglect); (3) re-victimization experiences, all in the context of (4) a lack of strategy, motivation, and practice in self-soothing. Adolescent dating violence (for a special issue, see Kerig 2010) is an issue overlapping with mental health and substance abuse in high risk populations (e.g., child welfare, juvenile justice; homeless), although accessing formalized support is less likely than receiving preventative services through school attendance. As with child maltreatment, effective and promising dating violence prevention programming exists (Wekerle and Tanaka 2010). The areas of the brain most sensitive to stress are those implicated in learning, memory, and "higher order" integration of emotions and thoughts needed to support executive functioning (Cicchetti and Curtis 2006; McCrory et al. 2010; Perry 2009). The chronic stress system dysfunction, from all maltreatment sources, challenges the core neurocognitive building blocks of emotional 
regulation, such that reactivity to trauma triggers and ambiguous threats, as well as reasoned action to potential threats, do not proceed in optimal emotion-cognition-behavior communication (De Bellis 2001; DeBellis 2002; DeBellis et al. 2010; DePrince et al. 2009; Lee and Hoaken 2007). With a dominating, global negative self, investment in personal learning and agency and confident exploration of the environment is advanced as impaired, leaving a further challenge to resilient functioning. Early intervention may be key.

Evidence shows that experiences in the 1st years of life are extremely important for a child's healthy development and lifelong learning. How a child develops during this time affects future cognitive, social, emotional, and physical development, which influences school readiness and later success in life. Research on a number of adult health and medical conditions points to predisease pathways that have their beginnings in early and middle childhood. (http://www.healthypeople.gov/2020/ topicsobjectives2020/default.aspx)

The US Healthy People 2020, the US priority-setting initiative, identifies as new priorities those that are consistent with the UN Rights of the Child (UNICEF 2003) and Milliennium Development Goals (http://www.un.org/millenniumgoals/bkgd.shtml), recognizing the needs for safety from violence, stable, safe and secure housing, and quality of life. This documents notes that adolescents (10-19 years) and young adults (20-24 years) represent about one-quarter of the US population and experiences during these developmental periods are foundational for setting in motion many adult chronic diseases. New target areas from earlier priority-setting include: (1) early and middle childhood; (2) adolescent health; (3) sexual minority persons' health, among others (http://www.healthypeople.gov/2020/top icsobjectives2020/default.aspx). In our own work with the Maltreatment and Adolescent Pathways (MAP) longitudinal study (three papers in these two volumes report on the MAP sample; Goldstein et al.; Stewart et al.; Weiss et al.), a sizeable minority of these child welfare-involved youths self-report lesbian, gay and bisexuality; many youth endorse "don't know" in response to the sexual orientation question. In a US population survey, maltreatment is elevated in lesbian women (Bradford et al. 1994), with $19 \%$ reporting incest, 32\% reporting childhood sexual abuse, and adult health issues are also reported (e.g., a third reporting daily tobacco smoking). The US Centers for Disease Control and Prevention identify two core public health goals: (1) prevention of violence to self and others; and (2) the promotion of safe, nurturing relationships. One area of particular challenge for youth with a history of child maltreatment, and especially childhood sexual abuse (CSA), is in the area of sexual relationships. Senn and Carey (2010) report that only CSA remains an individual predictor of adult risk (number of partners; proportion of unprotected sex episodes in a three-month period) when other forms of maltreatment and background factors are taken into account among females presenting to a publicly-funded clinic. Clearly, there is a greater need for understanding issues for under-studied groups and to conduct research directly with child welfare populations.

Not surprisingly, there are continuing calls for maltreatment prevention, especially in light of effective programs (e.g., MacMillan et al. 2009; MacMillan 2010). Emergent evidence suggests that in situations of increased predictability and structures for foster care youth (treatment foster care), stabilization of stress seems to be achievable (i.e., change from atypical to typical cortisol pattern, Fisher et al. 2007). This neurobiological resilience system reflects the adaptive capacity to interact with new environments and create new modes of responding and interacting that serve survival and development better (Cicchetti and Curtis 2006). This view draws heavily on the concepts of neural plasticity - wherein the experiences of the child fine tunes "the pattern of neuronal connections underlying the 
brain's function" (Weisel 1994; p. 1647), and self-organization-the reorganization of targeted brain systems to support adaptation in functioning when subjected to new constraints in the environment (Cicchetti and Curtis 2006; Cicchetti and Valentino 2006). Thus, with adversity comes opportunity. These first two volumes target current learning on a key risk factor - child maltreatment - and its relationship to mental health and substance abuse risks, while looking for those windows of opportunity where resilience may be evoked.

Acknowledgments I would like to acknowledge the following: (1) the collegiality of Masood Zangeneh; (2) the steadfast support from Ronald Chung; (3) the generosity of so many mental health, addiction, and child welfare front-line workers in sharing their expertise; and (4) all the many child, adolescent, and adult research subjects from whom I have learned so much and who I hope are benefitted by the research and its dissemination. There are many devoted, gracious persons working towards protecting our most vulnerable families.

\section{References}

Bradford, J., Ryan, C., \& Rothblum, E. D. (1994). National lesbian health care survey: Implications for mental health care. Journal of Consulting and Clinical Psychology, 62, 228-242.

Cicchetti, D., \& Curtis, J. W. (2006). The developing brain and neural plasticity: Implications for normality, psychopathology, and resilience. In D. Cicchetti \& D. J. Cohen (Eds.), Developmental psychopathology, vol 2: Developmental neuroscience (2nd ed.). Hoboken: Wiley.

Cicchetti, D., \& Valentino, K. (2006). An ecological transactional perspective on child maltreatment: Failure of the average expectable environment and its influence upon child development. In D. Cicchetti \& D. J. Cohen (Eds.), Developmental psychopathology (2nd ed.): Risk, disorder, and adaptation, vol. 3 (pp. 129201). Hoboken: Wiley.

Cicchetti, D., Rogosch, F. A., Sturge-Apple, M., \& Toth, S. L. (2009). Interaction of child maltreatment and 5-htt polymorphisms: Suicidal ideation among children from low-SES backgrounds. Journal of Pediatric Psychology, 37(5), 536-546.

Cooper, M. L., Russell, M., Skinner, J. B., \& Windle, M. (1992). Development and validation of a threedimensional measure of drinking motives. Psychological Assessment, 4(2), 123-132.

Currie, J., \& Widom, S. (2010). Long-term consequences of child abuse and neglect on adult economic wellbeing. Journal of Child Maltreatment, 15(4), 111-120.

De Bellis, M. D. (2001). Developmental traumatology: The psychobiological development of maltreated children and its implications for research, treatment, and policy. Development and Psychopathology, 13, 539-564.

DeBellis, M. D. (2002). Developmental traumatology: A contributory mechanism for alcohol and substance use disorders. Psychoneuroendocrinology, 27(1-2), 155-170.

DeBellis, M. D., Hooper, S. R., Woodley, D. P., \& Shenk, C. E. (2010). Demographic, maltreatment, and neurobiological correlates of ptsd symptoms in children and adolescents. Journal of Pediatric Psychology, 35(5), 570-577.

DePrince, A. P., Weinzierl, K. M., \& Combs, M. D. (2009). Executive function performance and trauma exposure in a community sample of children. Child Abuse \& Neglect: The International Journal, 33 (2009), 353-361.

Fallon, B., Trocme, N., \& Maclaurin, B. (2011). Should child protection services respond differently to maltreatment, risk of maltreatment and risk of harm? Child Abuse \& Neglect; The International Journal, 35(4), 236-239.

Finkelhor, D., Turner, H., Ormrod, R., \& Hamby, S. L. (2010). Trends in childhood violence and abuse exposure: Evidence from 2 national surveys. Archives of Pediatrics \& Adolescent Medicine, 164(3), $238-242$.

Fisher, P. A., Stoolmiller, M., Gunnar, M. R., \& Burraston, B. (2007). Effects of a therapeutic intervention for foster preschoolers on diurnal cortisol activity. Psychoneuroendocrinology, 32(8-10), 892-905.

Fiske, S. (2011). Envy up, scorn down: How status divides us. New York: Russell Sage. 
Gilbert, R., Widom, C. S., Browne, K., Fergusson, D., Webb, E., \& Janson, S. (2009). Burden and consequences of child maltreatment in high-income countries. Lancet, 373(9657), 68-81.

Gordis, E. B., Feres, N., Olezeski, C., Rabkin, A., \& Trickett, P. K. (2009). Skin conductance reactivity and respiratory sinus arrhythmia among maltreated and comparison youth: Relation with aggressive behavior. Journal of Pediatric Psychology, 35(5), 547-558.

Graham, I. D., Logan, J., Harrison, M. B., Straus, S. E., Tetroe, J., Caswell, W., et al. (2006). Lost in knowledge translation: Time for a map? The Journal of Continuing Education in the Health Professions, 26, 13-24.

Grant, V. V., Stewart, S. H., \& Mohr, C. D. (2009). Coping-anxiety and coping-depression motives predict different daily mood-drinking relationships. Journal of the Society of Psychologists in Addictive Behaviors, 23(2), 226-237.

Green, J. G., McLaughlin, K. A., Berglund, P. A., Gruber, M. J., Sampson, N. A., Zaslavsky, A. M., et al. (2010). Childhood adversities and adult psychiatric disorders in the National Comorbidity Survey replication I: Associations with first onset of DSM-IV disorders. Archives of General Psychiatry, 67(2), $113-123$.

Jacobson, C. M., \& Gould, M. (2007). The epidemiology and phenomenology of non-suicidal self-injurious behavior among adolescents: A critical review of the literature. Archives of Suicide Research, 11(2), 129147.

Kerig, P. K. (2010). Relational dynamics as sources of risk and resilience in adolescent dating violence: Introduction and overview. Journal of Aggression, Maltreatment \& Trauma, 19(6), 585-586.

Krug, E. G., Dahlberg, L. L., Mercy, J. A., Zwi, A. B., \& Lozano, R. (2002). World report on violence and health. Geneva: World Health Organization.

Kuntsche, E., Stewart, S. H., \& Cooper, M. L. (2008). How stable is the motive-alcohol use link? A crossnational validation of the drinking motives questionnaire revised among adolescents from Switzerland, Canada, and the United States. Journal of Studies on Alcohol and Drugs, 69(3), 388-396.

Laye-Gindhu, A., \& Schonert-Reich, K. A. (2005). Nonsuicidal self-harmamong community adolescents: Understanding the "whats" and "whys" of self-harm. Journal of Youth and Adolescence, 34, 447-457.

Lee, V., \& Hoaken, P. N. S. (2007). Cognition, emotion, and neurobiological development: Mediating the relation between maltreatment and aggression. Child Maltreatment, 12, 281-298.

MacMillan, H. L. (2010). Commentary: Child maltreatment and physical health: A call to action. Journal of Pediatric Psychology, 35(5), 533-535.

MacMillan, H. L., Wathen, C. N., Barlow, J., Fergusson, D. M., Leventhal, J. M., \& Taussig, H. N. (2009). Interventions to prevent child maltreatment and associated impairment. Lancet, 373(9659), 250-266.

McCrory, E., De Brito, S. A., \& Viding, E. (2010). Research review: The neurobiology and genetics of maltreatment and adversity. Journal of Child Psychology and Psychiatry, 51(10), 1079-1095.

McLaughlin, K. A., Green, J. G., Gruber, M. J., Sampson, N. A., Zaslavsky, A. M., \& Kessler, R. C. (2010). Childhood adversities and adult psychiatric disorders in the National Comorbidity Survey replication II: Associations with persistence of DSM-IV disorders. Archives of General Psychiatry, 67(2), 124-132.

Mildon, R., \& Shlonsky, A. (in press). Bridge over troubled water: Using implementation science to facilitate effective services in child welfare. Child Abuse \& Neglect: The International Journal

Perry, B. D. (2009). Examining child maltreatment through a neurodevelopmental lens: Clinical applications of the neurosequential model of therapeutics. Journal of Loss and Trauma, 14, 240-255.

Public Health Agency of Canada (2010). Canadian incidence study of reported child abuse and neglect2008: Major findings. Ottawa

Ross, S., \& Heath, N. L. (2003). Two models of adolescent self-mutilation. Suicide \& Life-Threatening Behavior, 33(3), 277-287.

Sadowski, L. S., Hunter, W. M., Bangdiwala, S. I., \& Munoz, S. R. (2004). The world studies of abuse in the family environment (WorldSAFE): A model of a multi-national study of family violence. International Journal of Injury Control and Safety Promotion, 11(2), 81-90. for the questionnaire, see Runyan, D.K., and the WorldSAFE Steering Committee. World Studies of Abuse and the Family Environment (WorldSAFE) Core Questionnaire. University of North Carolina at Chapel Hill. Chapel Hill, NC, 2001.

Senn, T. E., \& Carey, M. P. (2010). Child maltreatment and women's adult sexual risk behavior: Childhood sexual abuse as a unique risk factor. Journal of Child Maltreatment, 15(4), 324-335.

Stewart, S. H. (1996). Alcohol abuse in individuals exposed to trauma: A critical review. Psychological Bulletin, 120(1), 83-112.

Stewart, S. H., \& Israeli, A. L. (2002). Substance abuse and co-occurring psychiatric disorders in victims of intimate violence. In C. Wekerle \& A. M. Wall (Eds.), The violence and addiction equation: Theoretical and clinical issues in substance abuse and relationship violence (pp. 98-122). New York: BrunnerRoutledge. 
Taylor, C. A., Lee, S. J., Guterman, N. B., \& Rice, J. C. (2010). Use of spanking for 3-year-old children and associated intimate partner aggression or violence. Journal of Pediatrics, 126(3), 415-424.

Toth, S. L., \& Manly, J. (in press). Bridging research and practice: Challenges and successes in implementing evidence-based preventive intervention strategies for child maltreatment. Child Abuse \& Neglect: The International Journal

Trickett, P. K., Mennen, F. E., Kim, K., \& Sang, J. (2009). Childhood emotional maltreatment and later psychological distress among college students. Child Abuse \& Neglect: The International Journal, 33(1), 27-35.

Trocmé, N., Fallon, B., MacLaurin, B., Sinha, V., Black, T., Fast, E., Felstiner, C., Hélie, S., Turcotte, D., Weightman, P., Douglas, J., Holroyd, J. (2010). Canadian incidence study of reported child abuse and neglect: Characteristics of maltreatment, in Public Health Agency of Canada. Canadian Incidence Study of Reported Child Abuse and Neglect-2008: Major Findings. Ottawa, 2010

UNICEF. (2003). Children have rights. Retrieved June 4, 2011, from http://www.unicef.org/why/why_rights. html

Wall, A.-M., \& Mckee, S. (2002). Cognitive social learning models of substance use and intimate violence. In C. Wekerle \& A.-M. Wall (Eds.), The violence and addiction equation: Theoretical and clinical issues in substance abuse and relationship violence (pp. 123-149). New York: Brunner-Routledge.

Webb, W., Post, P., Robinson, B., \& Moreland, L. (1992). Self-concept, anxiety, and knowledge exhibited by adult children of alcoholics and adult children of non alcoholics. Journal of Alcohol and Drug Education, 20(1992), 106-114.

Weisel, T. (1994). Genetics and behavior. Science, 264, 1647.

Wekerle, C. (2011). Practical strategies: The dollars and senselessness in failing to prioritize childhood maltreatment prevention. Child Abuse \& Neglect: The International Journal, 35, 159-161.

Wekerle, C., \& Tanaka, M. (2010). Adolescent dating violence research and violence prevention: An opportunity to support health outcomes. Journal of Aggression, Maltreatment \& Trauma, 19(6), 681685 .

Wekerle, C., \& Wall, A.-M. (2002). The violence and addiction equation: Theoretical and clinical issues in substance abuse and relationship violence. New York: Brunner-Routledge.

Wekerle, C., \& Wolfe, D. A. (1993). Prevention of child physical abuse and neglect: Promising new directions. Clinical Psychology Review, 13, 501-540.

Wekerle, C., \& Wolfe, D. A. (1999). Dating violence in mid-adolescence: Theory, significance, and emerging prevention initiatives. Clinical Psychology Review, 19, 435-456.

Wekerle, C., Waechter, R., Leung, E., \& Leonard, M. (2007). Adolescence: A window of opportunity for positive change. First Peoples Child and Family Review, 3, 8-16.

Wekerle, C., Leung, E., MacMillan, H. L., Boyle, M., Trocmé, N., \& Waechter, R. (2009). The impact of childhood emotional maltreatment on teen dating violence. Child Abuse \& Neglect: The International Journal, 33, 45-58.

Wolfe, D. A., \& Wekerle, C. (1993). Treatment strategies for child physical abuse and neglect: A critical progress report. Clinical Psychology Review, 13, 473-500.

Yates, T., \& Wekerle, C. (2009). Special section on the impact of childhood emotional abuse. Editorial: The long-terms consequences of emotional maltreatment on development: (Mal)adaptation in adolescence and young adulthood. Child Abuse \& Neglect: The International Journal, 33, 24-25. 